\title{
Announcements
}

The Eighth Annual Meeting of the Society for the Study of Reproduction will be held Tuesday, July 22-Friday, July 25, 1975, at Colorado State University, Fort Collins, Colorado. In addition to sessions devoted to research papers, a symposium on 'Mechanisms of Protein Hormone Action' and the annual Carl Hartman lecture are scheduled. For additional information, please contact:

Dr. LLOYD C. FAULKNER Chairman, Local Committee, SSR Department of Physiology and Biophysics Colorado State University Fort Collins, CO 80521 (USA)

\section{Membership in the International Society of Neuroendocrínology}

The criteria for membership in the society are the following: (1) an interest in the society; (2) the holding of a position which permits active work in the field, and (3) evidence of significant contributions to neuroendocrinology. The latter criterion is satisfied by evidence of publications in the field and by the letters from two sponsors.

Those who wish to apply for membership should obtain copies of the membership application form from Dr. S. M. McCANN, Chairman, Membership Committee, Department of Physiology, University of Texas Health Science Center at Dallas, Southwestern Medical School, Dallas, TX 75214 (USA). Six copies of the application form, a curriculum vitae and two supporting letters should be sent under separate cover to Dr. McCann. When all information is available, it is circulated to the Membership Committee which consists of Drs. TALEISNIK, FLERKO, KoRdOn, SCHARRER and McCANN.

\section{International Congress of Psychoneuroendocrinology}

The 6th International Congress of the International Society of Psychoneuroendocrinology will be hosted by the University of Colorado School of Medicine and will be held at the Given Institute, Aspen, Colorado, Aug. 22-26,1975.

The general theme of the Congress is 'Neuroendocrine Mediation Between Environment and Behavior' and will focus on the following topics: (a) Cyclic rythms; (b) Modulation of behavior by administration of hormones; and (c) Alcoholism as a drug abuse.

The Congress will include formal symposia on these topics dealing with observations in animal and man. In addition, short communications on related subjects are invited. 370

Announcements

Further information may be obtained from Dr. ANTONIA VERNADAKIS, Organizing Committee Secretary, International Society of Psychoneuroendocrinology, Departments of Psychiatry and Pharmacology, University of Colorado School of Medicine, Denver, CO 80220 (USA).

\section{Acta Endocrìnologíca Congres}

The 10th Acta Endocrinologica Congress will be held in Amsterdam at the Free University from August 26 to 29, 1975.

The program includes nine symposia on current important topics within the scope of endocrinology. The congress should be of interest to all scientists in the field of clinical and experimental endocrinology. For further information and registration write to the Secretary-General, Dr.P. G. Smelik, Department of Pharmacology, Free University, Medical Faculty, Amsterdam-1011 (The Netherlands). 